2021, Volume 8, ID 479

Research Article

DOI: $10.15342 / \mathrm{ijms} .2021 .479$

\title{
Evaluation of Drug Use Practices Using WHO Core Drug Use Indicators at Pediatric Health Facilities, Kabul, Afghanistan
}

\author{
Ahmad Farid Habibyar a (iD), Hafiza Hamid ${ }^{\text {a }}$ (D), Nesar Ahmad Zahier ${ }^{\text {b }}$, Qand Agha Nazari ${ }^{\text {a }}$, Neha \\ Sharma $^{c}$, Navneet Khurana ${ }^{c}$

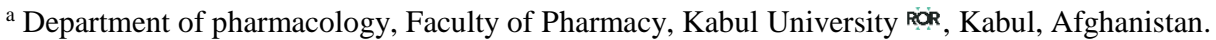 \\ b Department of Endocrinology, Ali Abad Teaching Hospital, Kabul University of Medical Sciences \\ (Abu Ali Ibn Sina) Rór , Kabul, Afghanistan. \\ c School of Pharmaceutical Sciences, Lovely Professional University Rör, Jalandhar - Delhi G.T. \\ Road, Phagwara, Punjab, India.
}

\begin{abstract}
Background: Irrational medicine use is a global problem. It can lead to increased morbidity and mortality and increased costs of drug therapy, thus imposing an adverse impact on the overall quality of the pharmaceutical care system. Objective: To evaluate drug use practices based on WHO core drug use indicators at pediatric health facilities of Kabul, Afghanistan. Objective: To evaluate drug use practices based on WHO core drug use indicators at pediatric health facilities of Kabul, Afghanistan.

Methods: A cross-sectional study was conducted at outpatient departments of the three pediatric health facilities at samples collected using a systematic random sampling method. The sample size included 600 outpatient prescriptions. Data were evaluated as per the WHO guidelines.

Results: On average, 2.795, 2.745, and 4.2 drugs per prescription were prescribed in 001, 002 , and 003 health facilities, respectively (WHO standard is 1.6-1.8). 37.03\% of drugs in $001,42.62 \%$ in 002 , and $42.64 \%$ of drugs in 003 were prescribed by the generic name (WHO standard is $100 \%$ ). Antibiotics were prescribed in $79 \%$ prescriptions of the $001,88 \%$ of the 002 , and $52 \%$ of the 003 health facilities (WHO standard value is $20-26.8 \%$ ). Injections were prescribed in $6 \%$ of the $001,32 \%$ of the 002 , and $19.5 \%$ of the 003 prescriptions (WHO standard is $13.4-24.1 \%$ ). $65.47 \%$ of drugs in $001,67.94 \%$ of drugs in 002 , and $73.1 \%$ of drugs in 003 health facilities were prescribed from the Afghanistan national essential medicines list (WHO standard is 100\%).

Conclusion: Most of the core drug use indicators were not met with WHO standards in these pediatric health facilities. However, in 001 and 003 health facilities, the prescribing patterns may be more complex because they are tertiary health care centers.
\end{abstract}

Keywords: Core Drug Use Indicators, Kabul, Pediatric, Drug Use Patterns.

Received: 14 mar 2021; Revised: 08 may 2021; Accepted: 31 may 2021; Published: 11 jun 2021

Correspondence: Qand Agha Nazari, Department of pharmacology, faculty of pharmacy, Kabul University, Kabul, Afghanistan. Email: qznazari@yahoo.com

Cite this article as: Habibyar AF, Hamid H, Zahier NA, Nazari QA, Sharma N, Khurana N. Evaluation of Drug Use Practices Using WHO Core Drug Use Indicators at Pediatric Health Facilities, Kabul, Afghanistan. Integr J Med Sci. 2021;8:479. [https://doi.org/10.15342/ijms.2021.479].

Copyright (C) 2021 Ahmad Farid Habibyar et al. This is an open access article distributed under the Creative Commons Attribution 4.0 International License, which permits unrestricted use, distribution, and reproduction in any medium, provided the original work is properly cited. 


\section{INTRODUCTION}

The concept of rational medicine use (RMU) includes proper prescribing, proper dispensing, and proper medication use by the patients for diagnosing, preventing, and treating various diseases. In addition, RMU states that the patients receive medicines according to their clinical needs, in doses that meet their own individual requirements, for an adequate period of time and at the lowest possible cost to them and their community. The main goal of RMU is to strengthen the pharmaceutical care system [1].

World Health Organization (WHO) has developed core and complementary drug use indicators. Among these, core drugs use indicators were used for the purpose of the present study. Because these indicators are less likely to fluctuate, feasible over time and place, and easy to measure drug use than using complementary indicators. Irrational use of medicine has been primarily observed in the health facilities of developing countries. According to WHO estimates, more than $50 \%$ of all drugs were irrationally prescribed or dispensed. More than $50 \%$ of the patients fail to use them rationally. Irrational medicine use is a global problem. It can lead to increased morbidity and mortality, adverse drug reactions, and increased costs of drug therapy, thus negatively impacting the overall quality of the pharmaceutical care system $[2,3]$.

The causes of irrational medicine use are vast and complicated, including the health care system, health professionals, patients, and community [1]. Therefore, it is required to evaluate the current drug use practices to generate the baseline data for future in-depth investigation of drug use, probe underlying reasons, design interventional strategies for implementation, and bring positive changes in the pharmaceutical care system in Afghanistan. Therefore, the present study aims to evaluate RMU by using WHO prescribing indicators in selected pediatric health facilities in Kabul, Afghanistan.

\section{METHODS}

Study design and setting

A quantitative cross-sectional study design was conducted to assess rational medicine use based on WHO prescribing indicators in the outpatient departments of three pediatric hospitals (001, 002, and 003) in Kabul, Afghanistan. This study was conducted from Oct 18th, 2016, to Oct 17th, 2017. 001 and 003 are tertiary pediatric hospitals, while 002 is a primary pediatric hospital. 001 and 002 are public hospitals, but 003 is not. Study population

All pediatric outpatient prescriptions dispensed from Oct 18th, 2016, to Oct 17th, 2017, were included in the present study. Those prescriptions given for medical supplies or laboratory tests or, in some cases, for adult patients were excluded from the present study.

Sample size and sampling method

Based on WHO guidelines for investigating drug use (WHO, 1993), in the present study, a total of 600 outpatient prescriptions were collected (200 medications from each health facility). A systematic random sampling method was used to select 200 pediatric drugs from each hospital.

Data collection technique

Before the start of the study, written consent from the administration of all three hospitals was acquired. A digital camera was used to capture the legible copy of pediatric prescriptions. In addition, the verbal consent of the patient parents was also taken. For core drug use indicators, data from the outpatient prescriptions were entered into the WHO prescribing indicator form.

Data quality control

One of the principal investigators, who was well trained in data collection, went into the pediatric hospitals and collected the data. Before collecting the data, their completeness and consistency were checked and ensured by the principal investigator.

Data analysis

Data were entered into the WHO prescribing indicator form designed in Ms. excel 2013. Then, it was analyzed using Ms. Excel 2013. Ultimately, the data were presented using a tabular presentation. The following WHO prescribing indicators were analyzed in the present study:

The average number of drugs per patient prescription. This is used to measure the degree of polypharmacy.

Calculation:

$$
\text { Average }=\frac{\text { total number of different drug products prescribed }}{\text { number of encounters surveyed }}
$$

Percentage of drugs prescribed by the generic name. It is used to measure the tendency to prescribe by the generic name. 
Calculation:

$$
\text { Percentage }=\frac{\begin{array}{c}
\text { number of drugs prescribe } \\
\mathrm{d} \text { by generic name }
\end{array}}{\text { total number of drugs prescribed }} \times 100
$$

Percentage of prescriptions with an antibiotic prescribed

Calculation:

$$
\text { Percentage }=\frac{\text { number of patient encounters with an antibiotc prescribed }}{\text { total number of encounters surveyed }} \times 100
$$

Percentage of prescriptions with an injection prescribed. These indicators are used to measure the overall level of use of two important but commonly overused and costly forms of drug therapy.

Calculation:

$$
\text { Percentage }=\frac{\text { number of patient encounters with an injction prescribed }}{\text { total number of encounters surveyed }} \times 100
$$

Percentage of drugs prescribed from the essential drugs list or formulary. This indicator is used to measure the degree to which practices conform to national drug policy, as indicated by prescribing from the national essential drugs list or formulary for the type of facility surveyed.

Calculation:

$$
\text { Percentage }=\frac{\text { number of products prescribed from essential drugs list }}{\text { total number of products prescribed }} \times 100
$$

\section{RESULTS}

In the following results of the analysis for 600 outpatient prescriptions of the three pediatric patients are presented:

Demographic data

The present study found that the average patient age in the health facility 001 was 3.9 years, and $57.5 \%$ of the patients were male, and $41.5 \%$ were female. In addition, the average patient age in the 002 health facility was 2.08 years, and $65.5 \%$ of the patients were male, and $33.5 \%$ were female. Finally, in the 003 health facility, it was found that the average patient age was 3.5 years, and $60.5 \%$ of the patients were male, and $39.5 \%$ were female (Table 1). According to this study, in all three pediatric health facilities, most of the patients were male.

\begin{tabular}{ccccc}
\hline \multicolumn{4}{c}{ Table 1: Demographic data of the pediatric patients at three Kabul city health facilities. } \\
\hline \multirow{2}{*}{ Health facility } & $\begin{array}{c}\text { Average patient age } \\
\text { (years) }\end{array}$ & $\begin{array}{c}\text { \% } \\
\text { Male }\end{array}$ & $\begin{array}{c}\text { \% } \\
\text { Female }\end{array}$ & $\begin{array}{c}\text { \% Age not } \\
\text { indicated }\end{array}$ \\
\hline 001 & 3.9 & 57.5 & 41.5 & 1 \\
002 & 2.08 & 65.5 & 33.5 & 1 \\
003 & 3.5 & 60.5 & 39.5 & - \\
\hline
\end{tabular}

Prescribing indicators

Based on WHO guidelines, a total of 600 prescriptions were analyzed from three pediatric health facilities.

Results of 001 health facility

In this health facility, the analysis of 200 outpatient pediatric prescriptions showed that a total of 559 drugs were prescribed. On average, 2.795 drugs were prescribed per prescription. $37.03 \%(n=207)$ of medicines were prescribed by the generic name, and $79 \%(n=158)$ of the prescriptions contained an antibiotic. Injections were prescribed in the $6 \%(\mathrm{n}=12)$ of the prescriptions. Moreover, $65.47 \% \quad(n=366)$ of the medicines were prescribed from Afghanistan's national essential medicines list (table 3).

Results of 002 health facility

The results of analysis from 200 outpatient prescriptions of the 002 health facility showed that a total of 549 medications were prescribed. On average, 2.745 medicines were prescribed per prescription. In addition, $42.62 \%$ of medicines $(n=234)$ prescribed by the generic name and $88 \%(n=176)$ of the prescriptions contained an antibiotic, and in $32 \%$ of the prescriptions $(n=64)$ injections were prescribed. Finally, 67.94\% $(n=373)$ of the medicines prescribed were from Afghanistan's national essential medicines list (table 3).

Results of 003 health facility

The results of analysis from 200 outpatient prescriptions from 003 health facility showed that a total of 840 medications were prescribed in the prescriptions obtained from 003 health 
facility. On average, 4.2 medicines were prescribed per prescription. In addition, $42.64 \%$ of medicines $(n=375)$ were prescribed by the generic name, and 52\% $(n=104)$ of the prescriptions contained an antibiotic, and in $19.5 \%(\mathrm{n}=39)$ of the prescriptions, injections were prescribed. Finally, $73.1 \%(n=614)$ of the medicines prescribed from Afghanistan's national essential medicines list (table 3). Table 2 shows the total number of medicines/prescriptions per health facility.

\begin{tabular}{lccc}
\hline Table 2: Total Number of medicines/prescriptions per health facility & & \\
\hline Health facility code number & 001 & 002 & 003 \\
Total number of drugs prescribed & 559 & 549 & 840 \\
Total number of drugs prescribed by the generic name & 207 & 234 & 375 \\
Total number of prescriptions containing an antibiotic & 158 & 176 & 104 \\
Total number of prescriptions containing an injections & 12 & 64 & 39 \\
Total number of medicines prescribed from & 366 & 373 & 614 \\
Afghanistan's national essential medicines list & & & \\
\hline
\end{tabular}

Table 3: Summary of results obtained from three outpatient prescriptions at Kabul pediatric health facilities, based on WHO core drug use indicators

\begin{tabular}{lcccc} 
WHO prescribing indicator & \multicolumn{3}{c}{ Health facility } & Optimal \\
\cline { 2 - 4 } value
\end{tabular}

\section{DISCUSSION}

Our study found that the average number of drugs per prescription was 2.795 in 001 health facilities, 2.745 in 002 health facilities. The highest value was 4.2 in 003 health facilities. The average number of drugs per prescription was higher than the WHO standard in all three health facilities. Ideally, it should be less than 2 (1.6-1.8). Although our finding is higher than the WHO standard, it is in range and even lesser than similar studies carried out elsewhere. For instance, similar studies conducted in India, Saudi Arabia, Nigeria, Jordan, and Sudan reported values of an average number of drugs per prescription were (5.6), (2.6), (2.6), (2.4), and (2), respectively [4-8].

The probable reasons behind overprescribing could be a lack of adequate knowledge and training of prescribers, poor prescribing practices, a symptomatic treatment approach, and the financial interest of the prescribers. Polypharmacy can lead to drug-drug interactions, adverse drug reactions, and increased health care costs. The percentage of drugs prescribed by the generic name was $37.03 \%$ in $001,42.62 \%$ in 002 , and $42.64 \%$ in 003 health facilities. Our finding is lower than the WHO standard (100\%). However, studies carried out elsewhere found that the percentage of drugs prescribed by the generic name was $2.6 \%$ in India, $49.3 \%$ in Sudan, and $68.9 \%$ in Nigeria [8,6,7]; our values fall in this range. Inadequate generic prescribing could lead to increased health care costs, and the problem of bioequivalence; therefore, it is required to promote the prescribing of generic drugs [9].

Furthermore, the percentage of encounters with an antibiotic prescribed was $79 \%$ in 001 health facility, $88 \%$ in 002 health facility, and $52 \%$ in 003 health facility. These values were higher than the optimal WHO value, which should be (20-26.8\%). On the other hand, this finding is in range with studies carried out in Sudan $(81.3 \%)$, Nigeria $(71.1 \%)$, and India $(81.1 \%)$ [6-8]. Overuse of antibiotics can lead to the emergence of antimicrobial resistance, which does not respond to the conventional antibiotics available at present [9].

Similarly, the percentage of prescriptions with injections prescribed was $6 \%$ in 001 health facility, $32 \%$ in 002 health facility, and $19.5 \%$ in 003 health facility. According to the WHO standard, this value should be between $13.4-24.1 \%$. In health facility 001 , the value is lower than the WHO standard. In 002 health facilities, the value is higher than the WHO standard. While similar studies carried out elsewhere, their reported values of injection prescription were $21.1 \%$ in Sierra Leone, $3.5 \%$ in Sudan, $21.8 \%$ in India $[8,10]$. Our values from two 
health facilities fall within this range. Overuse of injections can lead to the transmission of bloodborne diseases, including HIV/AIDS, Hepatitis B virus, Hepatitis C virus, increased drug-related costs, and pain at the injection site [11].

Finally, $65.47 \%$ of drugs in the 001 health facility were prescribed from Afghanistan's national essential drugs list. In 002 and 003 health facilities, this percentage was $67.94 \%$ and $73.1 \%$, respectively, while the WHO standard is $100 \%$. The essential drugs list can promote rational drug prescribing by selecting cost-effective drugs applicable to disease prevalence within a country. Similar studies in other countries reported that the percentage of drugs prescribed from their respective essential drugs list were $60.4 \%$ in Nigeria, $90.2 \%$ in India, and $100 \%$ in the United Arab Emirates [8.12-13].

Strengths and limitations

This is the first study based on WHO core drug use indicators on the outpatient pediatric prescriptions of Kabul, Afghanistan. It provides the basis to conduct further studies in this regard. This study indicates some aspects of prescribing practices in pediatric patients. Policymakers can design interventions to address the prescribing problems. This study is performed on specific WHO-approved core drug use indicators i.e., prescribing indicators. Further studies will be required to conduct upon all WHO-approved drug use indicators in pediatric settings. This study indicates what is being prescribed for the pediatric population, but it does not reflect its reason. Two of the health settings considered in this study, including 001 and 003 , are tertiary healthcare settings, and 001 health facility is primary healthcare. The prescribing patterns of the tertiary health care settings are more complex, and thus they require further in-depth investigation.

\section{CONCLUSION}

Our findings from three paediatric outpatient prescriptions analyses showed that current prescribing practices do not comply with the WHO standards. For instance, the average number of drugs per prescription was slightly higher than the WHO standard in 001 and 002 health facilities, but it was highest in 003 health facility than two health facilities and WHO standards. Prescribing by the generic name was not satisfactory in all health facilities. Antibiotics were overprescribed in all three health settings. Injections were under-prescribed in 001 health facility and overprescribed in 002 health facility, but it was in the standard range for 003 health facility. 100\% prescription of drugs from Afghanistan's national essential medicine list was not performed in all health care settings.

\section{HIGHLIGHTS}

The average number of drugs per prescription was slightly higher than the WHO standard in all health facilities.

Prescribing by the generic name was not satisfactory in all healthcare settings.

Antibiotics were overprescribed.

Injections were under-prescribed in one health facility, but on the contrary, it was overprescribed in another health facility. Still, it was in the standard range for 003 health facility. Prescribing from Afghanistan's national essential drugs list was lower than WHO standard in all health care facilities.

\section{Acknowledgments}

The authors acknowledge the institutional academic council and administration of faculty of pharmacy, Kabul University, and the administrations and Pharmacists of all the three pediatric health facilities who helped in any way to conduct the present study.

\section{Authors' contributions}

The participation of each author corresponds to the criteria of authorship and contributorship emphasized in the Recommendations for the Conduct, Reporting, Editing, and Publication of Scholarly work in Medical Journals of the International Committee of Medical Journal Editors. Indeed, all the authors have actively participated in the redaction, the revision of the manuscript, and provided approval for this final revised version.

Funding

No funding was received from any organization to conduct the present study.

Conflict of interest

The authors declare that there is no conflict of interest regarding the publication of this article. 
Ethical approval

Although this is not a direct human study, no patient identifying data were used in the present study, but still, the authors declare that all the ethical principles were obeyed while designing and conducting the present study. In the time this study was designed and conducted our institution did not had any research or ethics committee, but the protocol for the present study was officially approved by the institutional academic council (Reference no: 181-3/9/2016).

\section{REFERENCES}

[1] Management science for health. MDS-3: Managing access to medicines and health technologies. USA: Kumarian Press; 2012. pp.1.6, 3.6, 27.12. [Accessed 2021 Jun 9]. Available From : https://www.msh.org/sites/default/files/mds3-jan2014.pdf

[2] World Health Organization. How to investigate drug use in health facilities: selected drug use indicators. Geneva: World Health Organization (EDM research series no. 007); 1993. Chapter 2, Core drug use indicators. [Accessed 2021 Jun 9]. Available From: https://apps.who.int/iris/bitstream/handle/10665/60519/WHO_DAP 93.1.pdf ? sequence $=1 \&$ is Allowed $=\mathrm{y}$

[3] Sisay M, Abdela J, Kano Z, Araya M. Drug Prescribing and Dispensing Practices in Tertiary Care Hospital of Eastern Ethiopia: Evaluation with World Health Organization Core Prescribing and Patient Care Indicators. J Clin Exp Pharmacol. 2017 May; 7(3):1-8.

DOI: $10.4172 / 2161-1459.1000238$

[4] Mohajer KA, Al-Yami SM, Al-Jeraisy MI, Abolfotouh MA. Antibiotic prescribing in a pediatric emergency setting in central Saudi Arabia. Saudi Med J. 2011 Feb; 32 (2):197-8. [Accessed 2021 Jun 9]. Available From: https://smj.org.sa/content/smj/32/2/197.full.pdf

[5] Al-Niemat SI, Aljbouri TM, Goussous LS, Efaishat RA, Salah RK. Antibiotic prescribing patterns in outpatient emergency clinics at Queen Rania Al Abdullah II Children's Hospital, Jordan, 2013. Oman Med J. 2014 Jul; 29(4):250-4.

DOI: $10.5001 /$ omj.2014.67

[6] Ahmed AM, Awad AI. Drug use practices at pediatric hospitals of Khartoum State, Sudan. Ann Pharmacother. 2010 Dec; 44(12):1986-93.

DOI: $10.1345 / \mathrm{aph} .1 \mathrm{p} 423$

[7] Fadare JO, Olatunya O, Oluwayemi OI, Ogundare OE. Drug prescribing pattern for under-fives in a paediatric clinic in South-Western Nigeria. Ethiop J Health Sci. 2015 Feb; 25(1):73-8.

DOI: $10.4314 /$ ejhs.v25i1.10

[8] Akhtar MS, Vohora D, Pillai KK, et al. Drug prescribing practices in pediatric department of a North Indian university teaching hospital. Asian J Pharmand Clin Res. 2012 Mar; 5:146-9.

[9] World Health Organization (WHO). Introduction to Drug Utilization Research. Oslo, Norway: WHO International Working Group for Drug Statistics Methodology, WHO Collaborating Centre for Drug Statistics Methodology, WHO Collaborating Centre for Drug Utilization Research and Clinical Pharmacological Services; 2003; p.16. [Accessed 2021 Jun 9]. Available From: https://apps.who.int/iris/bitstream/handle/10665/42627/924156234X.pdf?sequence= 1\&isAllowed=

[10] Cole CP, James PB, Kargbo AT. An evaluation of the prescribing patterns for under five patients at a Tertiary Paediatric Hospital in Sierra Leone. J Clin Pharm. 2015 Sep; 6(4):109-14.

DOI: $10.4103 / 0976-0105.168051$

[11] World Health Organization. Worldwide country situation analysis: response to antimicrobial resistance. Geneva. 2015.

[12] Kumar SG, Adithan C, Harish BN, Sujatha S, Boy G, Malini A. Antimicrobial resistance in India: a review. J Nat Sci Biol Med. 2013 Jul; 4(2):286-91. DOI: $\underline{\text { 10.4103/0976-9668.116970 }}$

[13] Sharif IS, Nassar AH, Al-Hamami FK, Hassanein MM. Trends of pediatric outpatients prescribing in Umm Al Quwain, United Arab Emirates. Pharmacol pharm. 2015 Jan; 6(1):9-16.

DOI: $\underline{10.4236 / p p .2015 .61002}$ 